\title{
Enhanced expression of insulin receptor substrate-2 and activation of protein kinase B/Akt in regenerating pancreatic duct epithelium of $60 \%$-partial pancreatectomy rats
}

\author{
T. L. Jetton, Y. Q. Liu, W. E. Trotman, P. W. Nevin, X-J. Sun, J. L. Leahy \\ Division of Endocrinology, Diabetes and Metabolism, University of Vermont, College of Medicine, Burlington, VT, USA
}

\begin{abstract}
Aims/hypothesis. Early compensatory mechanisms of regeneration following partial pancreatectomy involve ductal proliferation and, subsequently, differentiation into acinar and endocrine cell types, although it is not clear how these processes are regulated. We investigated the expression and roles of insulin receptor substrate-2 (IRS-2) and protein kinase $\mathrm{B} / \mathrm{Akt}$ (Akt) in pancreatic regeneration that starts with the common duct epithelium using a non-diabetic model of beta cell adaptation and mass expansion, $60 \%$-pancreatectomy rats.

Methods. We used confocal immunofluorescence microscopy to study IRS-2 and Akt expression and activation in pancreatic common ducts at intervals after surgery. These proteins were studied in relation to proliferation markers and insulin immunostaining.

Results. In pancreatectomized rats, a short-term increase in proliferation was observed in the common duct epithelial lining ( $\sim$-fold) compared with sham-operated control rats which correlated with
\end{abstract}

about a 1.8 -fold increase in IRS-2 immunoreactivity 2 days after surgery. Interspersed with proliferating cells of the common duct, evaginations were rare single and clustered insulin immunopositive cells which expressed high levels of IRS-2 immunoreactivity. Epithelium of duct evaginations from 2-day post-Px rats exhibited striking phospho-Akt staining ( 3.5-fold above control rats) without any detectable changes in total Akt staining.

Conclusion/interpretation. Our data suggest that IRS2 plays an important role in pancreatic regeneration and growth by mediating duct proliferation and by maintaining the differentiated beta cell. The restricted staining pattern of phospho-Akt to cells of the common duct evaginations suggests that it has a role in regulating post-mitotic events related to cellspecific gene expression or survival or both. [Diabetologia (2001) 44: 2056-2065]

Keywords Pancreatectomy, pancreatic duct, regeneration, IRS-2, PKB/Akt, ductal proliferation.
The pancreatic beta cell regulates both the storage and metabolism of cellular fuels through secretion of insulin. Our studies and those of others have shown an enhanced number of beta cells in response to im-

Received: 13 April 2001 and in revised form: 20 June 2001

Corresponding author: J.L. Leahy, Division of Endocrinology, Diabetes and Metabolism, University of Vermont College of Medicine, Given C331, Burlington, VT 05405-0068, USA, e-mail: jleahy@zoo.uvm.edu

Abbreviations: Px, Partial pancreatectomy; IR, insulin receptor; IRS-1, IRS-2, insulin receptor substrates-1, 2; Akt protein Kinase B/Akt; MAPK, mitogen-activated protein kinases paired tissue insulin sensitivity [1,2], a lowered betacell mass following partial pancreatectomy $(\mathrm{Px})[3,4]$ or hyperglycaemia $[5,6]$. Beta-cell mass is determined by several factors including cell death and the recruitment of new cells by the replication of existing beta cells or by neogenesis from pancreatic ductal precursors [7]. The physiological regulation of these processes is not well understood; little is known in particular about the signalling mechanisms governing ductal proliferation, and subsequent endocrine differentiation and assembly into islets.

Fresh insights have come from gene knockout studies in mice that investigated the insulin receptor 
(IR) and post-receptor signalling cascade $[1,2,8]$. Heterozygous disruption of the $I R$ and $I R S-1$ caused insulin resistance but diabetes was mild and late in onset because of a compensatory increase in betacell mass [1]. In contrast, homozygous null mutation of $I R S$-2 caused a similar insulin resistance but diabetes was severe and early in onset due to a lack of the beta-cell compensatory growth response [9]. This suggests that IRS-2, which was previously thought to act principally in the classical insulin-sensitive tissues such as liver, muscle, and adipose, must also play a crucial role in beta-cell compensatory growth. It is now clear that the IR [10], IRS-1 [10-13] and IRS-2 $[10,14-16]$, and downstream components of the insulin signalling cascade are expressed in the beta cells [17-19]. Increased IRS-2 expression was found in beta-cell lines with enhanced proliferation capacity [14] and among ducts during pancreatic cancer [20]. Also, two key intermediates within the insulin signalling cascade, the lipid kinase phosphatidylinositol 3kinase (PI3-kinase) and the growth factor-activated serine/threonine protein kinase B/Akt (Akt), are involved in regulating beta-cell proliferation and differentiation through IGF-I stimulation [17-20]. Furthermore, IGF-1-stimulated beta-cell proliferation is probably mediated through IRS-2 [15]. However, to date, there are few reports on endogenously-activated Akt within the pancreas.

Islet neogenesis, as a form of postnatal beta-cell growth, has been reported following a $90 \%-\mathrm{Px}$ in rats [4]. During the first week after surgery these rats not only showed the anticipated hyperplasia of islet beta cells but also the presence of proliferating ductal epithelium which subsequently differentiated and formed acini, ducts, and islets thus reiterating the pattern observed during embryogenesis [4]. Px-stimulated islet neogenesis has therapeutic potential, because an adequate amount of functional islet tissue can be restored following beta-cell ablation by streptozotocin [22]. It is not clear if IRS-2 or Akt is involved in this process .

We examined pancreatic remnants in rats 1,2 and 5 days following a $60 \%$-Px to investigate potential roles for IRS- 2 and Akt in the common duct where growth responses originate. These $60 \%$-Px rats display a similar regeneration sequence as that of the $90 \%-P x$ rats but maintain normal plasma glucose concentrations making them an excellent model to investigate mechanisms of compensatory beta-cell adaptation [26,27].

\section{Materials and methods}

$60 \%$-Px rat model. Male Sprague-Dawley rats (90-120 g) underwent a $60 \%$-Px using our method previously described [26]. We followed the principles of animal laboratory care strictly using the guidelines of both the NIH and UVM's Animal Care
Committee. Briefly, the portion of the pancreas bordered by the spleen and stomach extending to the small flap attached to the pylorus was removed by gentle abrasion using cotton applicators. Rats were studied 1, 2 or 5 days post-surgery (unless stated otherwise) together with sham-operated control rats that had undergone laparotomy and mobilization of the pancreas on the same operation days. Body weight and non-fasting blood glucose concentrations were measured in rats before the Px surgery or sham surgery, and again on the day of study.

Tissue processing of pancreas for immunofluorescence. Px and sham pancreata (only the duodenal lobe of the shams was taken to ensure comparable anatomical areas) were rapidly excised and immersion-fixed overnight in $4.0 \%$ paraformaldehyde in $0.1 \mathrm{~mol} / 1 \mathrm{PBS}$ at $4{ }^{\circ} \mathrm{C}$. After washing in several changes of $0.1 \mathrm{~mol} / \mathrm{l} \mathrm{PBS}$ over $2 \mathrm{~h}$ at $4{ }^{\circ} \mathrm{C}$, tissues designated for IRS-2 staining were dehydrated in ascending ethanols and routinely infiltrated and embedded in paraffin. Five $\mu \mathrm{m}$ sections were mounted on charged microslides (Charge-Plus, Fisher Scientific, Pittsburgh, Penn., USA). For Akt staining, common pancreatic ducts were isolated by dissection from the whole pancreas under a stereoscope on ice and then paraformaldehyde-fixed. Duct tissue was washed and equilibrated in $30 \%$ sucrose/PBS, embedded in O.C.T. medium (Miles Scientific, Elkhart, Ind., USA), and sectioned at $5 \mu \mathrm{m}$ in a cryostat.

Multiple-labelling immunofluorescence. Hydrated sections of whole pancreas, or frozen sections of dissected common ducts were equilibrated in PBS. An antigen retrieval method was used for IRS-2 immunostaining (paraffin sections) that included a $10 \mathrm{~min}$ boil in $10 \mathrm{mmol} / \mathrm{l}$ sodium citrate or a $10 \mathrm{~min}$ incubation in $0.125 \%$ trypsin at $37^{\circ} \mathrm{C}$ (Zymed Laboratories South San Francisco, Calif., USA) before blocking in 5\% normal donkey serum $+1 \%$ BSA. Sections were incubated overnight at $40^{\circ} \mathrm{C}$ in various combinations of diluted rabbit antiserum raised against a GST-fusion peptide of mouse IRS-2 $2^{976-1094}$ [28], guinea pig anti-insulin (Linco Research, Charles, Mo., USA), and a nuclear counterstain, YoPro1 $(0.5 \mu \mathrm{g} / \mathrm{ml}$; Molecular Probes, Eugene, Ore., USA) or a proliferation marker (Ki67 [29]; PharminGen, San Diego, Calif., USA and PCNA [30]; Zymed Laboratories) to label replicating cells. Immunostaining of frozen secretions for activated signalling intermediates was accomplished with a battery of phospho-specific antibodies to the MAPK family (including MAPK [Erk1/2], p38 MAPK, and SAPK/JNK) (Cell Signaling Technology, Beverly, Mass., USA). Activated Akt labelling used a mouse monoclonal anti-phospho-S ${ }^{473}$ Akt (Cell Signaling Technology). Following washing, sections were incubated in a secondary antibody mixture that contained donkey anti-guinea pig CY2, donkey anti-rabbit CY2 or CY3 and donkey anti-mouse CY3 or CY5 (all from Jackson ImmunoResearch, Westgrove, Pa., USA) and mounted in Poly-AquaMount (Polysciences, Warrington, Pa., USA). Alternate sections were stained with either non-immune rabbit serum (replacing the IRS-2 antiserum in the series), normal donkey serum, or mouse monoclonal antibodies to irrelevant antigens. Controls for secondary antibody specificity were done as previously detailed [31].

Confocal imaging. Sections were imaged using a Bio-Rad MRC 1024 (Hercules, Calif., USA) scanning confocal head coupled to an upright Olympus BX50 (Melville, NY, USA) microscope with an Ar-Kr laser utilizing the 488-, 568-, and 647 $\mathrm{nm}$ excitation lines (UVM Cell Imaging Facility). Images were acquired with the Bio-Rad LaserSharp software (v.3.2), merged and formatted on a Power Macintosh running Adobe Photoshop 5.0 (San Jose, Calif., USA). 
Table 1. Plasma glucose concentration and body weight in $60 \%$-Px and sham-perated rats

\begin{tabular}{llcccc}
\hline Parameter & Rats & Surgery day & 1 day & 2 days & 5 days \\
\hline Plasma glucose $(\mathrm{mmol} / \mathrm{l})$ & Shams & $7.8 \pm 0.2(10)$ & $7.8 \pm 0.3(3)$ & $7.8 \pm 0.1(3)$ & $8.1 \pm 0.2(4)$ \\
& $60 \%-\mathrm{Px}$ & $7.8 \pm 0.1(23)$ & $7.7 \pm 0.2(8)$ & $8.4 \pm 0.1(7)$ & $7.9 \pm 0.1(8)$ \\
Delta body weight $(\mathrm{g})^{\mathrm{a}}$ & Shams & $108 \pm 4(11)$ & $13 \pm 5(4)$ & $22 \pm 8(3)$ & $42 \pm 2(4)$ \\
& $60 \%-P x$ & $111 \pm 3(23)$ & $-3 \pm 1(8)$ & $7 \pm 3(7)$ & $25 \pm 2(8)$ \\
\hline
\end{tabular}

Data are presented as means \pm SEM. Rats underwent sham-Px or $60 \%-\mathrm{Px}$ as described in the text. Plasma glucose and body weight measurements were made on the morning of the surgery and again 1, 2 or 5 days after surgery; thus each post-surgery group is unique, with the number of animals in brackets.

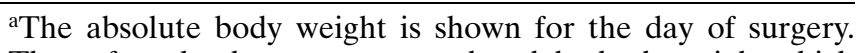
Thereafter, the data are expressed as delta body weight which was calculated as the weight on the day of study after surgery minus the weight of that rat on the day of surgery
Control experiments for IRS-2 and Akt expression. CHO cells that overexpress the human insulin receptor $(\mathrm{CHO} / \mathrm{IR})$ and mouse IRS-2 (CHO/IR/IRS-2) or rat Akt (CHO/IR/Akt) were grown in Ham's F-12 medium with $10 \%$ fetal bovine serum [32]. Cells were grown overnight in DMEM (no serum) with $25 \mathrm{mmol} / \mathrm{l}$ glucose prior to stimulating with $100 \mathrm{nmol} / \mathrm{l}$ insulin. They were then rinsed and fixed in $4.0 \%$ paraformaldehyde in $10 \mathrm{mmol} / 1 \mathrm{PBS}$ at room temperature for $30 \mathrm{~min}$ followed by immunofluorescence studies for IRS-2 and total Akt/phospho-Akt using the same protocol for the tissue sections. Alternatively, cells were lysed in the following buffer: $20 \mathrm{mmol} / \mathrm{l}$ Tris- $\mathrm{HCl}, \mathrm{pH}$ 7.5, $137 \mathrm{mmol} / \mathrm{l} \mathrm{NaCl}, 100 \mathrm{mmol} / \mathrm{l}$ $\mathrm{NaF}, 1 \mathrm{mmol} / 1 \mathrm{MgCl}_{2}, 1 \mathrm{mmol} / \mathrm{l} \mathrm{CaCl} 2,200 \mu \mathrm{mol} / 1$ sodium orthovanadate, $0.4 \mathrm{mmol} / \mathrm{l} \mathrm{PMSF}, 50 \mu \mathrm{g} / \mathrm{ml}$ aprotinin, $50 \mu \mathrm{g} / \mathrm{ml}$ leupeptin, $10 \%$ glycerol and $1 \%$ NP-40 and centrifuged at $13000 \mathrm{rpm}$ for $15 \mathrm{~min}$ for immunoblot analyses.

Immunoblots were done using a variation of a previously described methods [32]. Isolated common pancreatic ducts were homogenized in $80 \mathrm{mmol} / \mathrm{l} \mathrm{HEPES}, \mathrm{pH} 7.4,0.5 \% \mathrm{NP} 40,0.5 \%$ Triton X-100, $5 \mathrm{mmol} / \mathrm{l}$ EDTA, $50 \mu \mathrm{g} / \mathrm{ml}$ leupeptin, $50 \mu \mathrm{g} / \mathrm{ml}$ aprotinin, $1 \mathrm{mmol} / \mathrm{l}$ phenylmethylsulfonylfluoride, and $200 \mu \mathrm{mol} / \mathrm{l}$ sodium orthovanadate, and centrifuged at $12000 \mathrm{~g}$ for $15 \mathrm{~min}$. Samples were heated at $95^{\circ} \mathrm{C}$ for $5 \mathrm{~min}$ in Laemmli sample buffer and aliquots run on 7.5 or $10 \%$ SDS-PAGE, then transferred to nitrocellulose membranes. The IRS-2 immunoblots of the $\mathrm{CHO}$ lysates and duct homogenates were done with and without immunoprecipitation with rabbit anti-IRS-2 followed by probing with HRP-conjugated protein $\mathrm{G}$ (Calbiochem San Diego, Calif., USA) for $30 \mathrm{~min}$. Total Akt and phospho-Akt levels were measured in duct supernatants and $\mathrm{CHO}$ lysates using a rabbit anti-Akt or mouse anti-phospho-S ${ }^{473} \mathrm{Akt}$ (Cell Signaling Technology) followed by incubation in either goat antirabbit-HRP or goat anti-mouse-HRP (Jackson ImmunoResearch). Following development with SuperSignal substrate (Pierce, Rockford, Ill., USA), bands were detected by exposure to BioMax MR film (Eastman-Kodak, Rockford, Ill., USA).

Quantification of IRS-2 in common duct epithelium. A semiquantitative comparison of IRS-2 immunoreactivity in the common duct was accomplished by batch staining and sampling by confocal microscopy. Samples were imaged with the confocal microscope using a $60 \times$ PlanApo objective lens (N. A. $=1.4)$ and the $568 \mathrm{~nm}$ excitation line of a ArKr laser. For each field, the microscope was focused to maximize the number of common duct cells optically sectioned through the middle of the nucleus. All confocal imaging parameters were identical for each imaged field with 4-7 non-overlapping fields of about $190 \times 190 \mu \mathrm{m}$ captured for each Px and sham pancreas ( $n=4$ per group). Grayscale images $(512 \times 512$ pixels $)$ were transferred to a Power Macintosh G3 running NIH Image (v 1.62 NIH, USA) for image analysis. For each field studied, the Area-Measure tool was used to outline the entire epithelial sheet of the common duct (excluding goblet cells and luminal material), distinguishing between the main (luminal) lining and the adjacent blind evaginations. The mean pixel intensity (range $=0-255$ grayscale levels) of the IRS-2 immunofluorescence was measured separately for the duct luminal lining and associated evaginations for each rat after subtraction of the field background fluorescence values.

Proliferation rates of the common duct epithelium. The relative numbers of common duct cells undergoing replication in the Px and sham rats were estimated by confocal imaging with the proliferation marker Ki-67 superimposed on a nuclear counterstain. The percentage of Ki-67 labelled duct cells was measured separately in the common duct lining and adjacent buds by counting an average of about 220 duct cells/pancreas ( $n=4$ per group).

Phospho-Akt and insulin in common duct epithelium. Using the same strategy as above, phospho-Akt was superimposed with a nuclear counterstain in frozen sections of isolated common ducts to determine the percentages of phospho-Akt-positive duct cells. Because epithelium from isolated common ducts was limited, the results are based on pooled data from 4-6 Px and sham rats to obtain approximately 875 cells for each group.

\section{Results}

General characteristics of $60 \%-P x$ rats. The body weight and $0900 \mathrm{~h}$ plasma glucose concentrations of ad libitum fed $60 \%$-Px and sham-operated rats 1,2 and 5 days post surgery are shown in Table 1 . Neither body weight nor plasma glucose concentrations were different in the Px and sham groups before surgery. Glycaemia did not change following the $60 \%$-Px surgery except for a minor increase at 2 days $(p<0.003$ when pre surgery and 2-day post-Px glycaemia values in the same rats were compared using a paired Student's $t$ test, and $p<0.01$ when 2-day sham and 2-day Px rats were compared by unpaired Student's $t$ test). Body weight decreased after the Px surgery but returned to normal growth rate by the second day. This finding agrees with our previous observations of normal to slightly subnormal body weights in $60 \%$-Px rats 3-6 weeks post surgery [26].

Ductal hyperplasia and insulin expression in Px rats. There was a substantial increase in proliferation of the common duct epithelium after the $60 \%$-Px sur- 

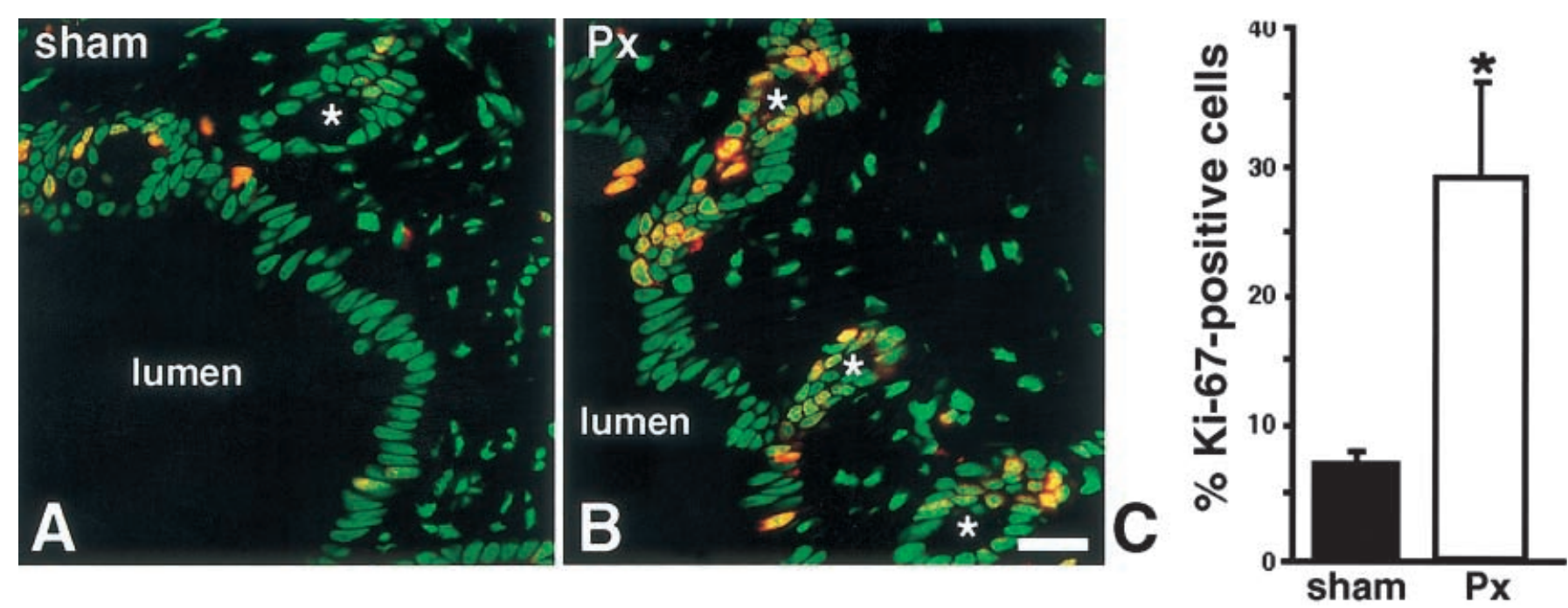

Fig 1 A-C. Comparison of proliferation in common pancreatic ducts in Px rats 2 days after surgery. (A) Representative field of the common duct luminal lining of a sham-operated rat showing a few Ki-67 + cells (orange nuclei). Non-proliferating nuclei are colored green. Duct epithelial evaginations are indicated (*). (B) Comparable field from a Px rat 2 days after surgery showing considerably more Ki-67+ cells. (C) The percentage of replicating duct cells of the duct lining was measured by counting Ki-67 + cells out of the total number of luminal duct cells. This epithelium had increased ( $\sim$-fold; $P=0.024)$ proliferation in the Px group 2 days after surgery (*) compared to the sham group

gery (Fig. 1A, B). The percentage of proliferating common duct cells was estimated using the proliferation marker $\mathrm{Ki}-67$ and a nuclear counterstain (Fig. 1C). At day 2 following the $60 \%$-Px, the proliferation rate of the duct luminal lining epithelium increased about fourfold in the Px rats compared with the sham-operated control rats $(p=0.024)$. No significant differences were observed between the Px and sham rats at 1 or 5 -days after surgery (data not shown).

Single endocrine cells, or endocrine cell clusters that expressed insulin and, less often, pancreatic polypeptide or glucagon, were found to be widely scattered among the epithelium of the common pancreatic duct and its lateral evaginations (see below). These hormone-positive cells were not unique to Px rats but were more frequently encountered in these than in the control rats. However, a meaningful statistical analysis was not possible because these cells were scattered so widely. Thus, both increased ductal proliferation and beta-cell neogenesis were observed in the common duct of 2-day post-Px rats. We then focused on the potential role of the insulin signalling pathway in these processes.

IRS-2 and Akt immunoreactivity in $\mathrm{CHO}$ cells. The specificity of the IRS-2 and Akt antibodies were test- ed in IRS-2- and Akt-overexpressing $\mathrm{CHO} / \mathrm{IR}$ cells using immunofluorescence and immunoblot detection. The $\mathrm{CHO} / \mathrm{IR}$ cells showed low endogenous IRS-2, Akt and phospho-Akt (Fig. 2). But the expected increases in IRS-2 immunoreactivity in the $\mathrm{CHO}$ / IR/IRS-2 cells (Fig. 2A) and Akt immunoreactivity in $\mathrm{CHO} / \mathrm{IR} / \mathrm{Akt}$ cells (Fig. 2B) could be clearly seen with both methods. After insulin stimulation, a marked increase in phosphorylated (activated) Akt immunoreactivity was observed using the phosphoAkt antibody which was at the correct molecular weight for Akt according to the immunoblot analysis (Fig. 2C) with no change in total Akt immunoreactivity.

IRS-2 in the common pancreatic ducts. We investigated IRS-2 expression in the common duct of 2-day Px rats using immunoblot and immunofluorescence. Immunoblot analysis of IRS-2 immunoprecipitates of dissected duct homogenates revealed a single band at the expected molecular mass of IRS-2 but no difference in band intensity between the Px and sham rats (data not shown). In contrast, IRS-2 immunofluorescence revealed a marked difference in signal intensity between the Px and sham rats 2 days after surgery at this same timepoint. Low to moderate IRS-2 staining intensity was evident in the duct epithelium of the control rats (Fig. 3A) as opposed to much higher IRS-2 staining intensity in Px rats (Fig. 3B). Quantification of the IRS-2 staining intensity using batch staining and image analysis, selectively measuring only the ductal epithelium, showed a 1.71-fold $(p=0.013)$ and 1.83-fold $(p=0.008)$ increase in the 2-day Px group compared with sham group for the common duct luminal cells and budding evaginations, respectively (Fig. 3E). The increase in IRS-2 immunostaining was specific to the common duct epithelium of Px rats 2 days after Px surgery, as adjacent acinar tissue (Fig. 3A,B) and small ducts showed equivalent low-intensity staining in both groups. Moreover, 
A
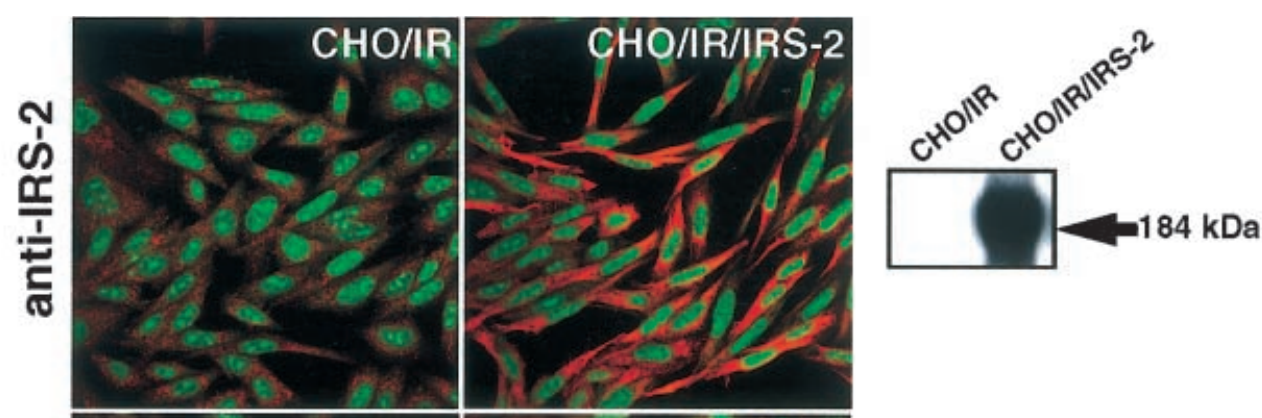

B
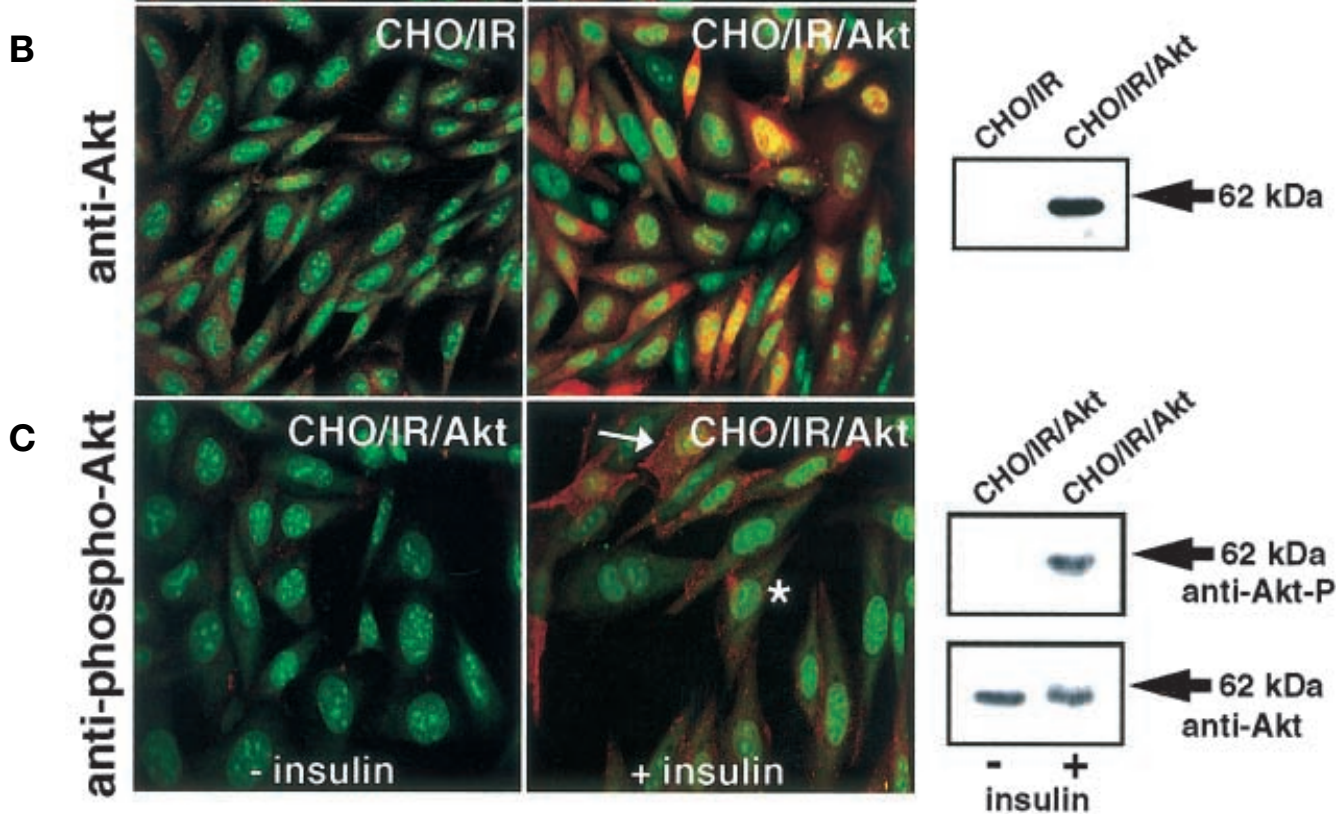

Fig 2 A-C. IRS-2, Akt, and phospho-Akt expression in $\mathrm{CHO}$ cells. $\mathrm{CHO} / \mathrm{IR}$ and double transfected $\mathrm{CHO} / \mathrm{IR} / \mathrm{IRS}-2$ and $\mathrm{CHO} / \mathrm{IR} / \mathrm{Akt}$ cells were fixed and stained by immunofluorescence or lysed and subjected to immunoblot analysis. Antibodies are indicated on the left. (A) $\mathrm{CHO} / \mathrm{IR}$ cells have low endogenous IRS-2 immunoreactivity (red fluorescence), while $\mathrm{CHO} / \mathrm{IR} / \mathrm{IRS}-2$ cells have very high signal. Nuclei are counterstained green. Immunoblot analysis confirms identity of IRS-2 as reactive band at $\sim 185 \mathrm{kDa}$. (B) Analysis of $\mathrm{CHO} / \mathrm{IR} / \mathrm{Akt}$ cells results in heightened Akt immunofluorescence signal and an increase in the corresponding $\sim 60 \mathrm{kDa}$ band. (C) $\mathrm{CHO} / \mathrm{IR} / \mathrm{Akt}$ subjected to $15 \mathrm{~min}$ insulin stimulation followed by analysis with phospho-Akt antibody. Phospho-Akt signal was observed in a range of staining patterns including surfaceoriented (arrow) and perinuclear-compartmentalized (*). Immunoblot (A) using same antibody shows presence of a single band representing phospho-Akt upon insulin stimulation. Same blot was stripped and re-probed with anti-(total) Akt (lower) which yielded $\sim 60 \mathrm{kDa}$ bands in both lanes.

the IRS-2 signal was often intense in those duct cells that were proliferating, as shown by co-staining with a nuclear marker associated with replication (Fig.3C). Increases in IRS-2 staining was also observed in all single cells (Fig. 3D) or cell clusters that expressed insulin as well as islet beta cells (not shown). However, the virtual lack of staining with the proliferation marker, PCNA, suggests that these ductal insulin + /IRS-2 + cells were probably post-mitotic (Fig. 3D). Hence, heightened IRS-2 immunostaining intensity was observed in the common duct epithelium in Px rats 2 days after surgery and was especially strong in all associated cells that expressed insulin, presumably nascent, differentiated beta cells.

Akt expression in ducts. We then investigated expression and activation of some candidate downstream intermediates of the insulin-receptor/IRS and growth factor cascades in dissected ducts from Px and sham rats 2 days after surgery. This was accomplished using phospho-specific antibodies against Akt and key members of the MAPK family (see Methods section). We could find no reproducible staining patterns in the duct epithelia with any of the phospho-MAPK antibodies in either the Px or sham rats. On the other hand, phospho-Akt immunoreactivity was markedly increased within the epithelia of common duct evaginations in the Px rats: while $9 \%$ of these cells from control rats stained for phospho-Akt (Fig. 4A), 32\% were immunopositive in the Px group (Fig. 4B). Immunoblot analysis of duct homogenates for both phospho- and total Akt revealed about $60 \mathrm{kDa}$ bands, the expected mass of Akt (not shown). In contrast to the normalization of common duct IRS-2 immunoreactivity at 5 days post-surgery, phospho-Akt staining 

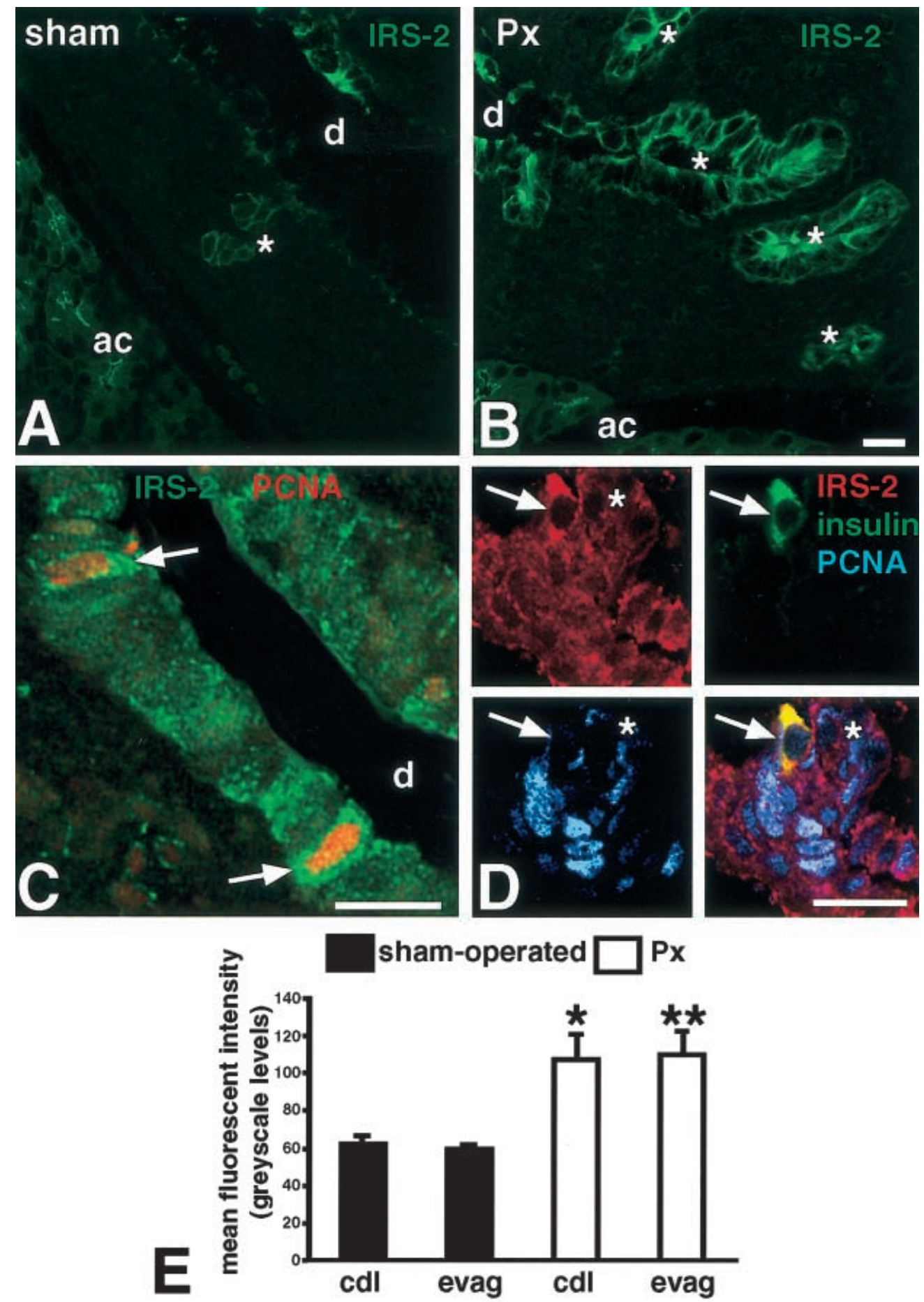

Fig 3 A-E. IRS-2 immunoreactivity associated with common pancreatic duct epithelium post $60 \%$ Px. (A) A representative section through the common duct from a sham-operated control rat exhibits IRS-2 immunoreactivity of low intensity in the epithelial lining. A branching epithelial evagination (*) surrounded by connective tissue as well as the apical face of acinar cells (ac) also show IRS-2 staining. Duct lumen (d) is indicated. (B) A comparable section to that in (A) from a 2 day post-Px rat showing considerable enhancement of IRS-2 immunostaining among the duct epithelium including the evaginations (*). No difference was observed in IRS-2 staining in acinar cells (ac). (C) Common duct epithelium from a Px rat 2 days after surgery double-stained for IRS-2 (green) and PCNA (red) to mark proliferating cells. (D) A field of the re- generating common duct from a Px rat 2 days after surgery at the junction between the luminal lining and an evagination $(*)$ stained for IRS-2 (red, upper left), insulin (green, upper right), and PCNA (blue, bottom left). Note that the frank insulin-positive cell (arrow) has little or no nuclear PCNA staining. Insulin-positive cells (arrow) express high levels of IRS-2 immunoreactivity as evidenced by their yellow-green emission color when images are superimposed (bottom right). Scale bars represent $20 \mu \mathrm{m}$. (E) Semi-quantitative analysis of IRS-2 immunoreactivity in common duct epithelium of Px and control rats 2 days after surgery, differentiating between the main lining (cpl) and adjacent evaginations revealed a 1.71-fold (*, $p=$ 0.013 ) and 1.83 -fold $(* *, p=0.008)$ increase in the IRS-2 intensity of the common duct lining and evaginations, respectively 

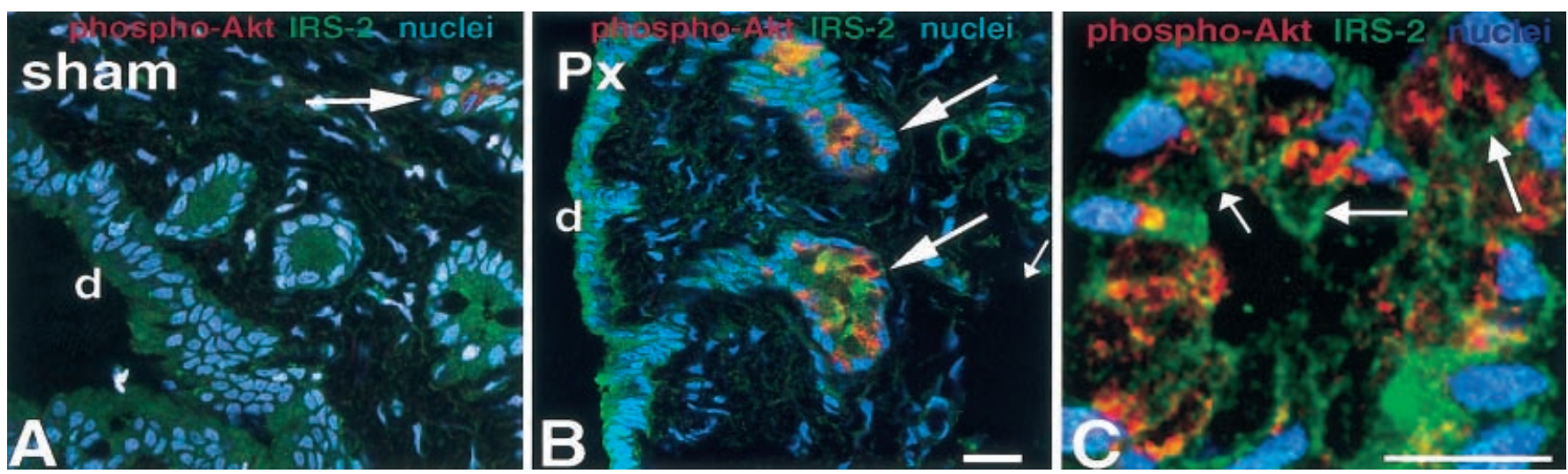

Fig 4A-C. IRS-2 and phospho-Akt immunostaining in the common pancreatic duct of Px rats 2 days after surgery. (A) A typical field of the common duct from a sham-operated control rat stained for IRS-2 (green) and activated (phospho-) Akt (red). Note that one evagination $(*)$ has a cluster of cells that stain for phospho-Akt (arrow). Nuclei are counterstained blue. (B) Overview of a comparable field of the common duct from a Px rat. The number of epithelial evaginations comprised of cell clusters with phospho-Akt staining has increased (arrows). (C) Higher magnification view of an evagination showing conspicuous cell clusters with surface-oriented IRS-2 (arrows) and strong phospho-Akt staining (red). Scale bars equal $20 \mu \mathrm{m}$.

remained high 5 days after surgery (not shown). Ductal cells with phospho-Akt staining often showed a surface-oriented pattern in IRS-2 staining in (Fig. 4C) in contrast to the mostly cytoplasmic pattern observed in the majority of the common duct epithelial cells. Phospho-Akt immunoreactivity did not correlate with proliferating duct cells, as suggested by the consistent lack of co-staining with proliferation markers (data not shown). Phospho-Akt immunoreactive cells also failed to stain for amylase and most were islet hormone-negative even 5 days after surgery, although some had modest levels of insulin immunopositivity (not shown). However, definitive insulin-positive cells were phospho-Akt-negative.

In contrast to activated Akt, immunostaining for total Akt resulted in a diffuse pattern of similar intensity in the ducts of sham and Px rats (not shown). Thus, phospho-Akt immunoreactivity marks specific non-proliferating cells of the evaginated common duct epithelium which have increased in number 2 days after Px surgery.

\section{Discussion}

Prompted by recent studies highlighting the importance of the insulin signalling pathway in beta-cell growth, maintenance and differentiation [1, 2, 8-16], we examined IRS- 2 and activated Akt in situ in relation to early common duct epithelial proliferation and insulin expression in a genetically normal, nondiabetic model of pancreatic regeneration and betacell adaptation, the $60 \% \mathrm{Px}$ rat. Studies on IRS-2 knockout mice show an inadequate beta-cell compensatory growth response to increased insulin resistance indicating that IRS- 2 has proliferation and survival roles in the beta cell $[1,8,9]$. However, it is not clear whether the loss of IRS-2 function affects these mice during fetal pancreatic islet development or postnatally or both. Because IRS-2 expression increases in highly proliferative beta-cell lines [14] and pancreatic tumors [20], there is now evidence linking IRS-2 with mitogenic signalling in beta cells. Previous studies in animals and humans have found IRS-2-expression in the pancreatic duct epithelium $[9,20]$, although the role of IRS-2 in regeneration and betacell neogenesis has not been directly addressed. Our results demonstrate that $60 \%$-Px rats show increased IRS-2 immunostaining in common duct epithelium which correlates with increased proliferation of this tissue, and that higher phospho-Akt levels are due to increased cell numbers with activated Akt staining among the common duct evaginations. Hence, both signalling proteins could function in mediating early events of pancreatic regeneration. However, whether these two proteins function independently or within a common signalling pathway remains an open question.

Following Px surgery, a very active replication of the common duct epithelium which correlated with enhanced IRS-2 immunoreactivity took place. Both events were short term and occurred over an identical timeframe. Surprisingly, of the three epithelial components of the pancreas (islet endocrine, acinar, and ducts), we could detect differences in IRS-2 immunoreactivity by semi-quantitative immunofluorescence only in the larger ducts 2 days following Px surgery. We observed about a 1.7-fold increase in IRS-2 immunoreactivity which coincided with a fourfold increase in proliferation in the common duct lining. Differences in IRS-2 levels in the common ducts among Px and control groups were not found using immunoblot because dissected duct preparations were not pure epithelial sheets but contained sub- 
stantial connective tissue and trace amounts of acinar tissue, both of which express IRS-2 by immunohistochemical detection. However, the significant increase in IRS-2 immunofluorescence signal corresponds with the short-lived proliferation "burst" reported in the common ducts of the $90 \%$-Px rat model $36 \mathrm{~h}$ after surgery [4]. Interestingly, in this same model and timeframe, a short-term rise in IGF-I mRNA expression in the regenerating ductal epithelium has been observed [33]. Thus, following a partial pancreatectomy, locally-borne IGF-I might be the triggering ligand that initiates or increases the duct proliferation response or both through the IRS-2 pathway. Increased in IRS-2 levels 2 days after surgery further indicate that this site is the initial focus of regeneration [4].

The epithelial lining of the pancreatic ducts serves as the source of exocrine and islet tissue during embryonic development, and, postnatally, during islet neogenesis which occurs less-frequently in the lifespan of the animal [7]. If a complete developmental recapitulation occurs during regeneration, then duct cells should serve as progenitors for all epithelium of the regenerating pancreas. However, within the narrow timeframe of the current study (1 to 5 days), we saw no evidence for acinar cell differentiation in the common ducts, as suggested by the observation that there were no amylase-positive cells among the duct epithelium. We did find increased but nevertheless low numbers of non-proliferating insulin-positive cells among the budding epithelium of Px rats which also showed strong IRS-2 immunoreactivity. Because all islet beta cells show cytoplasmic IRS-2 immunoreactivity [34] and our unpublished results), IRS-2 could have a maintenance role by promoting survival or the delay of apoptosis [1].

IRS-2 staining increased in proliferating common duct epithelium following Px but phospho-Akt immunoreactivity was observed, in contrast, in distinct, non-replicating but closely-associated cells of the evaginations. In many duct cells with strong phospho-Akt staining, IRS-2 immunoreactivity showed no increase in intensity. Instead, a surface-oriented localization suggestive of an activated state associated with the plasma membrane was found. Future studies are needed to determine whether this IRS-2 staining pattern in duct cells correlates with enhanced IRS-2 phosphorylation/activation.

The precise functional roles of both PI3-kinase and Akt are still not clear although they have been linked to IGF-I-stimulated beta-cell replication [17-19] and mass expansion in vivo [21]. We found little or no phospho-Akt immunostaining in islets with hyperproliferating beta cells (data not shown) and we could not detect either differences in total Akt levels in islets or ducts between Px and sham-operated rats using immunostaining. The consistent observation of increased numbers of non-proliferating
phospho-Akt + duct cells in Px rats 2 days after surgery could reflect enhanced insulin/growth factor signalling through this intermediate in certain duct cells. Some of these cells express low levels of insulin but not amylase suggesting that Akt could regulate differentiation signals, as opposed to its presumed role in beta-cell lines where Akt mediates proliferation from stimulation by insulin, IGF-I, or GLP-1 [18,19]. It is not clear if these particular duct cells are betacell progenitors during regeneration.

There is some evidence that activated MAPKs can function in glucose-dependent, beta-cell activities [35-37] but their role in beta-cell growth and differentiation is not clear. We examined the expression of three activated MAPKs (including Erk1/2, p38 MAPK, and SAPK/JNK) using immunofluorescence and found no correlation with IRS-2 staining patterns in the pancreatic ducts. The IGF-I receptor [39] seems to be the most important of the three known insulin receptor-family tyrosine kinases on the surfaces of beta cells in mediating beta-cell compensatory growth and proliferation [1], although the expression of these three receptors (insulin receptor [10-13], insulin receptor-related receptor [38] and the IGF-I receptor) in ducts of the adult pancreas has not been investigated.

Phospho-Akt immunostaining in the common duct epithelium was more extensive in Px rats than in the sham-operated control rats suggesting that specific duct cells show increased Akt signalling by $48 \mathrm{~h}$ after surgery. These cells were also present in the control rats, although in much smaller quantities $(\sim 30 \%$ of Px value). Once activated, Akt translocates and is targeted to specific cellular domains to undertake a variety of functions such as the regulation of metabolism, suppression of apoptosis and control of translation and transcription (see [40-42] for recent reviews). We are currently exploring the possibility that activated Akt in ducts could target factors that regulate growth and survival or cell-specific gene expression, or both. Indeed, transgenic mice that overexpress a constitutively active Akt isoform driven by the insulin promoter were observed to have an eightfold increase in betacell mass [21], although it is not clear whether beta-cell neogenesis increased in this model.

Conclusions. Our results indicate that IRS-2 has multiple roles in influencing early regeneration events in the Px model. These include the proliferation of common duct cells, as well as the possible maturation of certain duct cells into beta cells or the maintenance of the differentiated beta-cell phenotype, or both. The restricted expression of activated-Akt to cells of the budding common duct epithelium suggests that Akt could function in pancreatic regeneration by providing signals which result in cell-specific gene expression or survival, possibly by signalling through IRS-2. 
Acknowledgements. This work was supported by a grants from the National Institutes of Health DK56818 (J.L.Leahy) and by the American Diabetes Association (X.-J.Sun). We thank Dr. R. Zhande for helpful discussions on this project.

\section{References}

1. Withers DJ, Burks DJ, Towery HH, Altamuro SL, Flint CL, White MF (1999) Irs-2 coordinates Igf-1 receptor-mediated $\beta$-cell development and peripheral insulin signaling. Nat Genet 23: 32-40

2. Bruning JC, Winnay J, Bonner-Weir S, Taylor SI, Accili D, Kahn CR (1997) Development of a novel polygenic model of NIDDM in mice heterozygous for IR and IRS-1 null alleles. Cell 88: 561-572

3. Lee HC, Bonner-Weir S, Weir GC, Leahy JL (1989) Compensatory adaption to partial pancreatectomy in the rat. Endocrinology 124: 1571-1575

4. Bonner-Weir S, Baxter LA, Schuppin GT, Smith FE (1993) A second pathway for regeneration of adult exocrine and endocrine pancreas. Diabetes 42: 1715-1720

5. Bonner-Weir S, Deery D, Leahy JL, Weir GC (1989) Compensatory growth of pancreatic beta-cells in adult rats after short-term glucose infusion. Diabetes 38: 49-53

6. Bernard C, Thibault C, Berthault M-F et al. (1998) Pancreatic $\beta$ cell regeneration after 48 -h glucose infusion in mildly diabetic rats is nor correlated with functional improvement. Diabetes 47: 1058-1065

7. Bonner-Weir S (2000) Islet growth and development in the adult. J Mol Endocrinol 24: 297-302

8. Kido Y, Burks BJ, Withers D et al. (2000) Tissue-specific insulin resistance in mice with mutations in the insulin receptor, IRS-1, and IRS-2. J Clin Invest. 105: 199-205

9. Withers DJ, Gutierrez JS, Towery H et al. (1998) Disruption of the IRS-2 gene causes type 2 diabetes in mice. Nature 391: 900-904

10. Velloso LA, Carneiro EM, Crepaldi SC, Boschero AC, Saad MJ (1995) Glucose- and insulin-induced phosphorylation of the insulin receptor and its primary substrates IRS-1 and IRS-2 in rat pancreatic islets. FEBS Lett 377: 353-357

11. Rothenberg PL, Willison LD, Simon J, Wolf BA (1995) Glucose-induced insulin receptor tyrosine phosphorylation in insulin-secreting beta-cells. Diabetes 44: 802-809

12. Harbeck MC, Louie DC, Howland J, Wolf BA, Rothenberg PL (1996) Expression of insulin receptor mRNA and insulin receptor substrate 1 in pancreatic islet beta-cells. Diabetes 45: 711-717

13. Xu GG, Rothenberg PL (1998) Insulin receptor signaling in the beta-cell influences insulin gene expression and insulin content: evidence for autocrine beta-cell regulation. $\mathrm{Di}$ abetes 47: 1243-1252

14. Schuppin GT, Pons S, Hügl S et al. (1998) A specific increased expression of insulin receptor substrate 2 in pancreatic beta-cell lines is involved in mediating serum-stimulated beta-cell growth. Diabetes 47: 1074-1085

15. Hugl SR, White MF, Rhodes C J (1998) Insulin-like growth factor I (IGF-I)-stimulated pancreatic $\beta$-cell growth is glucose-dependent. J Biol Chem 273: 17771-17779

16. Zhang Q, Berggren PO, Hansson A, Tally M (1998) Insulin-like growth factor-I-induced DNA synthesis in insulinsecreting cell line RINm5F is associated with phosphorylation of the insulin-like growth factor-I receptor and the insulin receptor substrate-2. J Endocrinol 156: 573-581

17. Buteau J, Roduit R, Susini S, Prentki M (1998) Glucagonlike peptide-1 promotes DNA synthesis, activates phos- phatidylinositol 3-kinase and increases transcription factor pancreatic and duodenal homeobox 1 (PDX-1) DNA binding activity in beta (INS-1)-cells. Diabetologia 42: 856-864

18. Holst LS, Mulder H, Manganiello Vet al. (1998) Protein kinase $\mathrm{B}$ is expressed in pancreatic $\beta$ cells and activated upon stimulation with insulin-like growth factor I. Biochem Biophys Res Commun 250: 181-186

19. Trumper K, Trumper A, Trusheim H, Arnold R, Goke B, Horsch D (2000) Integrative mitogenic role of protein kinase B/Akt in beta-cells. Ann N Y Acad Sci 921: 242-250

20. Kornmann M, Maruyama H, Bergmann U et al. (1998) Enhanced expression of the insulin receptor substrate-2 docking protein in human pancreatic cancer Cancer Res 58: 4250-4254

21. Tuttle RL, Birnbaum MJ (2000) Overexpression of constitutively active Akt1 in the pancreatic beta cell improves glucose tolerance. Diabetes 49 [Suppl]LB-L16 (Abstract)

22. Hardikar AA, Karandikar MS, Bhonde RR (1999) Effect of partial pancreatectomy in diabetic status in BALB/c mice. J Endocrinol 162: 189-195

23. Sander M, German MS (1997) The beta cell transcription factors and development of the pancreas. J Mol Med 75: 327-340

24. Edlund H (1998) Transcribing pancreas. Diabetes 47: $1817-1823$

25. Huang HP, Tsai MJ (2000) Transcription factors involved in pancreatic islet development. J Biomed Sci 7: 27-34

26. Leahy JL, Bonner-Weir S, Weir GC (1988) Minimal chronic hyperglycemia is a critical determinant of impaired insulin secretion after an incomplete pancreatectomy. J Clin Invest 81: 1407-1414

27. Liu YQ, Nevin PW, Leahy JL (2000) Beta-cell adaptation in $60 \%$ pancreatectomy rats that preserves normoinsulinemia and normoglycemia. Am J Physiol Endocrinol Metab 279: E68-E73

28. Patti ME, Sun XJ, Bruening JC et al. (1995) 4PS/insulin receptor substrate (IRS)-2 is the alternative substrate of the insulin receptor in IRS-1-deficient mice. J Biol Chem 270: 24670-24673

29. Cattoretti G, Becker MH, Key G et al. (1992) Monoclonal antibodies against recombinant parts of the Ki-67 antigen (MIB1 and MIB3) detect proliferating cells in microwaveprocessed formalin-fixed paraffin sections. J Pathol 168: 357-363

30. Waseem NH, Lane DP (1990) Monoclonal antibody analysis of the proliferating cell nuclear antigen (PCNA). Structural conservation and the detection of a nucleolar form. J Cell Sci 96: 121-129

31. Jetton TL, Liang Y, Pettepher CC et al. (1994) Analysis of upstream glucokinase promoter activity in transgenic mice and identification of glucokinase in rare neuroendocrine cells in the brain and gut. J Biol Chem 269: 3641-3654

32. Sun XJ, Goldberg JL, Qiao L-Y, Mitchell JJ (1999) Insulininduced insulin receptor substrate-1 degradation is mediated by the proteosome degradation pathway. Diabetes 48: 1359-1365

33. Smith FE, Rosen KM, Villa-Komaroff L, Weir GC, Bonner-Weir S (1992) Enhanced insulin-like growth factor I gene expression in regenerating rat pancreas. Proc Natl Acad Sci USA 88: 6152-6156

34. Withers DJ, Gutierrez JS, Towery H et al. (1998) Disruption of the IRS-2 gene causes type 2 diabetes in mice. Nature 391: 900-904

35. Persaud SJ, Wheeler-Jones CPD, Jones PM (1996) The mitogen-activated protein kinase pathway in rat islets of Langerhans: studies on the regulation of insulin secretion. Biochem J 313: 119-124 
36. Khoo S, Cobb MH (1997) Activation of mitogen-activated protein kinase by glucose is not required for insulin secretion. Proc Natl Acad Sci USA 94: 5599-5604

37. Benes C, Roisin MP, Tan HV, Creuzet C, Miyazaki J-I, Fagard R (1998) Rapid activation and nuclear translocation of mitogen-activated protein kinases in response to physiological concentration of glucose in the MIN6 pancreatic $\beta$ cell line. J Biol Chem 273: 15507-15513

38. Hirayama I, Tamemoto H, Yokota, H, Kubo SK, Wang J, Kuwano H, Nagamachi Y, Takeuchi T, Izumi T (1999) Insulin receptor-related receptor is expressed in pancreatic beta-cells and stimulates tyrosine phosphorylation of insulin receptor substrate-1 and -2. Diabetes 48: 1237-1244
39. Fehmann H-C, Jehle P, Markus U, Goke B (1996) Functional active receptors for insulin-like growth factors-I (IGF-I) and IGF-II on insulin-, glucagon-, and somatostatin-producing cells. Metabolism 45: 759-766

40. Whitehead JP, Clark SF, Urso B, James DE (2000) Signalling through the insulin receptor. Curr Opin Cell Biol 12: 222-228

41. Vanhaesebroeck B, Alessi DR (2000) The PI3K-PDK1 connection: more than just a road to PKB. Biochem J 346: $561-576$

42. Downward J (1998) Mechanisms and consequences of activation of protein kinaseB/Akt. Curr Opin Cell Biol 10: 262-267 